\title{
Airway hyperresponsiveness to methacholine, adenosine 5-monophosphate, mannitol, eucapnic voluntary hyperpnoea and field exercise challenge in elite cross-country skiers
}

\author{
Malcolm Sue-Chu, ${ }^{1,2}$ John D Brannan, ${ }^{3}$ Sandra D Anderson, ${ }^{3}$ Nora Chew, ${ }^{4}$ Leif Bjermer ${ }^{5}$
}

'Department of Lung

Medicine, St Olavs Hospital,

University Hospital of

Trondheim, Trondheim,

Norway

${ }^{2}$ Department of Circulation and Imaging, Norwegian University of Science and Technology,

Trondheim, Norway

${ }^{3}$ Department of Respiratory

Medicine, Royal Prince Alfred

Hospital, Sydney, Australia

${ }^{4}$ School of Pharmacy,

University of Sydney, Sydney, Australia

${ }^{5}$ Department of Respiratory Medicine and Allergology,

University of Lund, Lund,

Sweden

\section{Correspondence to}

Dr Malcolm Sue-Chu,

Department of Lung Medicine

St Olavs Hospital, University

Hospital of Trondheim,

N-7006 Trondheim, Norway;

msuechu@online.no

Accepted 3 February 2010

Published Online First

10 May 2010

\begin{abstract}
Background Methacholine hyperresponsiveness is prevalent in elite athletes. Comparative studies have hitherto been limited to methacholine, eucapnic voluntary hyperpnoea and exercise. This study investigated airway responsiveness to these stimuli as well as to adenosine $5^{\prime}$-monophosphate (AMP) and mannitol, in 58 cross-country ski athletes.

Methods Exhaled nitric oxide concentration $\left(F_{E} N O\right)$, spirometry and bronchial challenge in random order with methacholine, AMP and mannitol were consecutively performed on three study days in the autumn. Specific $\lg \mathrm{E}$ to eight aeroallergens and a self-completed questionnaire about respiratory symptoms, allergy and asthmatic medication were also performed on day 1. Eucapnic voluntary hyperventilation (EVH) and field exercise tests were randomly performed in 33 of the skiers on two study days in the following winter.
\end{abstract}

Results Of 25 (43\%) skiers with airway hyperresponsiveness (AHR), 23, five and three skiers were hyperresponsive to methacholine, AMP and mannitol, respectively. Methacholine hyperresponsiveness was more prevalent in subjects without asthma-like symptoms. The $\mathrm{F}_{\mathrm{E}} \mathrm{NO}$ was not significantly different in skiers with and without methacholine hyperresponsiveness. Four of 14 skiers with and four of 19 skiers without methacholine hyperresponsiveness were hyperresponsive to EVH or exercise challenge. AHR to any stimulus was present in 16 asymptomatic and nine symptomatic skiers. Asthma-like symptoms were not correlated with AHR to any stimulus.

Conclusions Methacholine hyperresponsiveness is more common in asymptomatic skiers and is a poor predictor of hyperresponsiveness to mannitol and hyperpnoea. The low prevalence of hyperresponsiveness to indirect stimuli may suggest differences in the pathogenesis of methacholine hyperresponsiveness in elite skiers and non-athletes.

Highly trained athletes commonly report respiratory symptoms, asthmatic medication use, asthma, airway hyperresponsiveness (AHR) and exercise-induced bronchoconstriction (EIB). ${ }^{1-7}$

AHR to indirect stimuli, such as exercise, eucapnic voluntary hyperventilation (EVH), hypo or hypertonic aerosols and adenosine $5^{\prime}$-monophosphate (AMP) is considered to be more specific for asthma than hyperresponsiveness to a direct stimulus such as methacholine. $\mathrm{EVH}$ is more sensitive than sport-specific field exercise or methacholine provocation and is the preferred test of the Medical Commission of the International Olympic Committee for the detection of EIB. ${ }^{8-10}$ Provocation with dry powder mannitol has recently been proposed as an alternative to EVH. ${ }^{11}$

Studies comparing airway responsiveness to different stimuli in elite athletes have hitherto been restricted to methacholine, EVH and fieldbased or laboratory exercise. ${ }^{9} 1213$ In this study, we assessed AHR to methacholine, AMP and mannitol before and to EVH and a field exercise test during the competitive season and their association with self-reported respiratory symptoms, exhaled nitric oxide concentration $\left(\mathrm{F}_{\mathrm{E}} \mathrm{NO}\right)$ and allergic sensitisation in elite Norwegian crosscountry skiers.

\section{METHODS}

\section{Subjects and study design}

The study population consisted of 58 non-smoking cross-country and biathlon ski athletes (table 1). All subjects and parents of subjects under 18 years of age gave written informed consent. The study was approved by the Regional Ethics Committee in Trondheim.

$\mathrm{F}_{\mathrm{E}} \mathrm{NO}$, spirometry and bronchial provocation were consecutively performed on three study days in the autumn before the competitive season. The test sequence with methacholine, AMP and mannitol was determined by random allocation. A self-administered questionnaire on training hours, competitive experience, respiratory symptoms, allergy, use of asthmatic medication within the past year and asthma diagnosis and venepuncture were performed on day 1 .

All subjects were invited 3-4 months later at approximately 1 month after the start of the competitive season for an EVH and a sport-specific field exercise test on two additional study days. Two subjects withdrew for personal reasons and 23 subjects did not complete the study, because of a current or recent upper respiratory tract infection or training commitments.

\section{Bronchial provocation tests}

Subjects were instructed to refrain from vigorous exercise within $4 \mathrm{~h}$ and using short-acting $\beta_{2}$ agonists, cromones and ipratropium within $8 \mathrm{~h}$, long-acting $\beta_{2}$ agonists and antihistamines within $48 \mathrm{~h}$ and leucotriene receptor antagonists within 96 h of testing. Caffeine-containing drinks 
Table 1 Characteristics of study population

\begin{tabular}{|c|c|c|c|c|}
\hline & \multirow[b]{2}{*}{ All subjects } & \multicolumn{2}{|c|}{$\begin{array}{l}\text { Methacholine } \\
\text { hyperresponsiveness }\end{array}$} & \multirow[t]{2}{*}{ p Value } \\
\hline & & Positive & Negative & \\
\hline $\mathrm{N}$ (male) & $58(36)$ & $23(13)$ & $35(23)$ & NS \\
\hline Age, mean (SD), years & $18.1(1.7)$ & $17.9(2.0)$ & $18.2(1.4)$ & NS \\
\hline Height, mean (SD), cm & $174.8(8.7)$ & $171.8(8.7)$ & $176.7(8.2)$ & 0.04 \\
\hline Weight, mean (SD), kg & $65.7(10.4)$ & $63.0(10.7)$ & $67.5(9.9)$ & NS \\
\hline Weekly training, mean (SD), h & $11.7(2.6)$ & $11.3(1.9)$ & $12.0(3.0)$ & NS \\
\hline Competitive experience, mean (SD), years & $8.2(2.4)$ & $8.1(2.7)$ & $8.3(2.1)$ & NS \\
\hline Self-reported allergy & $16(27 \%)$ & $8(35 \%)$ & $8(23 \%)$ & NS \\
\hline Positive AlaTOP screen & $20(35 \%)$ & $11(48 \%)$ & $9(26 \%)$ & NS \\
\hline Asthma-like symptomatology & $26(45 \%)$ & $7(30 \%)$ & $19(54 \%)$ & NS \\
\hline Doctor-diagnosed asthma & $10(17 \%)$ & $4(17 \%)$ & $6(17 \%)$ & NS \\
\hline Medication within past 12 months & $19(33 \%)$ & $6(26 \%)$ & $13(37 \%)$ & NS \\
\hline$\beta_{2}$ Agonist & $11(20 \%)$ & $6(26 \%)$ & $5(14 \%)$ & NS \\
\hline Inhaled corticosteroids & $6(10 \%)$ & $2(9 \%)$ & $4(11 \%)$ & NS \\
\hline Antihistamines & $2(3 \%)$ & $0(0 \%)$ & $2(6 \%)$ & NS \\
\hline
\end{tabular}

and inhaled corticosteroids were discouraged on the test day. Bronchial provocation was not performed within 6 weeks of an upper respiratory tract infection.

To control for diurnal variation in lung function, all tests were to be conducted at approximately the same time of day, defined as a maximal time difference of 90 min or less on any of two study days.

Lung function was assessed by spirometry (MasterScope spirometer; Erich Jaeger $\mathrm{GmbH}$ and Co KG, Hoechberg, Germany). The better of two measurements with less than $5 \%$ variation was recorded. Predicted normal values were based on reference values of Crapo et al. ${ }^{14}$

Doubling dose increments of methacholine $2.5 \mathrm{mg} / \mathrm{ml}$ (four increments) and $25 \mathrm{mg} / \mathrm{ml}$ (two increments) and AMP $25 \mathrm{mg} / \mathrm{ml}$ (four increments) and $250 \mathrm{mg} / \mathrm{ml}$ (three increments) were administered from the Spira Elektro 2 automatic inhalation synchronised dosimeter jet nebuliser (Respiratory Care Centre, Hameenlinna, Finland) by a controlled tidal volume breathing technique. ${ }^{7} 15$ The cumulative dose of methacholine and AMP were $1814 \mu \mathrm{g}$ and $50.5 \mathrm{mg}$, respectively. Spirometry was performed $90 \mathrm{~s}$ after each increment and $180 \mathrm{~s}$ after the final increment. The test was terminated if the fall in the forced expiratory volume in $1 \mathrm{~s}\left(\mathrm{FEV}_{1}\right)$ was $20 \%$ or greater of the $\mathrm{FEV}_{1}$ measured after the inhalation of $0.9 \% \mathrm{NaCl}$.

A dry powder preparation of mannitol was delivered in gelatine capsules containing $0,5,10,20$ or $40 \mathrm{mg} .{ }^{16}$ Consecutive doses of $0,5,10,20,40,80,160,160$ and $160 \mathrm{mg}$ to a cumulative dose of $635 \mathrm{mg}$ were administered via an inhalator (Boehringer Ingelheim $\mathrm{GmbH}$, Ingelheim, Germany) and a controlled deep inhalation to total lung capacity with $5 \mathrm{~s}$ of breathholding. Spirometry was performed $60 \mathrm{~s}$ after each dose. The test ended if the fall in $\mathrm{FEV}_{1}$ was $15 \%$ or greater of the $\mathrm{FEV}_{1}$ after inhalation of $0 \mathrm{mg}$ mannitol or $635 \mathrm{mg}$ had been inhaled.

For the EVH test, a dry gas mixture of $21 \%$ oxygen and $5 \%$ carbon dioxide in nitrogen (AGA AS, Oslo, Norway) at room temperature was administered through a mouthpiece attached to a bacterial filter, pneumotachograph, two-way nonrebreathing valve (T-Shape 2700; Hans Rudolph Inc, Shawnee, Kansas, USA) and two reservoir bags in series. Gas flow was regulated so that the bags were always fully inflated. With the help of a metronome subjects were encouraged to achieve a respiratory rate of 40 breaths/min and a minute ventilation of $30 \times$ baseline $\mathrm{FEV}_{1}$. The latter was measured at $30 \mathrm{~s}$ intervals.
The average minute ventilation over the test duration of $8 \mathrm{~min}$ was calculated. Spirometry was performed before and at 3, 5, 7,10 and 20 min after challenge.

The sport-specific field exercise test consisted of a ski run at competition intensity without a warm-up. Subjects were sent out in pairs whenever possible. The course was $4.7 \mathrm{~km}$ long and at a height of $118 \mathrm{~m}$, increasing to a maximum height of $186 \mathrm{~m}$ over sea level at $1.8 \mathrm{~km}$ from the start. The ambient temperature varied from -13 to $+2^{\circ} \mathrm{C}$. Spirometry was performed before and at 5, 10, 15, 20 and 30 min after challenge.

Salbutamol $0.4 \mathrm{mg}$ (Airomir Autohaler; 3M Pharma, UK) was administered if the $\mathrm{FEV}_{1}$ decline exceeded $15 \%$ after methacholine, AMP and mannitol and always at 20 and 30 min, respectively, after EVH and the sport-specific exercise tests. Spirometry was performed 10 min postadministration.

\section{Allergic sensitisation}

Serum was examined with the AlaTOP allergy screen (Immulite 2000; Diagnostic Products Corporation, Los Angeles, California, USA) for specific IgE to house dust mite, cat, dog, horse, timothy grass and birch pollens, mugwort and cladosporium. Sensitisation was defined as a specific IgE concentration of $0.7 \mathrm{IU} / \mathrm{ml}$ or greater.

\section{Exhaled nitric oxide concentration}

$\mathrm{F}_{\mathrm{E}} \mathrm{NO}$ was measured before challenge with methacholine, AMP and mannitol with the LR 2000 nitric oxide chemiluminescence analyser (Logan Research Ltd, Rochester, UK). ${ }^{17}$ Briefly, subjects exhaled from total lung capacity to residual volume at an expiratory flow rate of $250 \mathrm{ml} / \mathrm{s}$ and against a target resistance of 4-5 cm water with the help of a biofeedback monitor. $\mathrm{F}_{\mathrm{E}} \mathrm{NO}$ was the average of three measurements of the plateau of the exhaled nitric oxide curve.

\section{Definitions}

Asthma-like symptomatology was defined as wheeze and abnormal breathlessness or chest tightness, either on exertion, at rest or on exposure to irritants within the past year.

AHR to methacholine was defined as a provocative dose causing a $20 \%$ fall in $\mathrm{FEV}_{1}$ of $1814 \mu \mathrm{g}$ or less, AMP as a provocative dose causing a $20 \%$ fall in $\mathrm{FEV}_{1}$ of $50.5 \mathrm{mg}$ or less and mannitol as a provocative dose causing a $15 \%$ fall in $\mathrm{FEV}_{1}$ of $635 \mathrm{mg}$ or less. AHR to EVH and sport-specific exercise 
challenge was defined as a fall in $\mathrm{FEV}_{1}$ over two time points of $10 \%$ or greater from baseline.

Ski asthma was defined as the presence of asthma symptomatology and AHR to methacholine.

\section{Statistics}

Statistical testing was performed with GraphPad Prism 4.02 for Windows. Differences in subject characteristics were analysed with the Student's t test for normally distributed data, Mann-Whitney $U$ test for non-normally distributed data or the $\chi^{2}$ test (two-tailed p. Fisher's exact test when appropriate). Spirometry data were normally distributed and analysed by repeated measures analysis of variance and Tukey's multiple comparison test for all pairs of columns. $\mathrm{F}_{\mathrm{E}} \mathrm{NO}$ data were not normally distributed and were analysed with Friedman's test and Dunn's multiple comparison test. Correlation coefficients were calculated using Spearman's rank method. Statistical significance was defined as a p value of 0.05 or less.

\section{RESULTS}

All tests were performed without complications. For methacholine, AMP and mannitol tests the mean (range) interval was 29.5 (6-50) days. The mean maximal time difference for testing was $106(0-405)$ min on any of two study days and within $90 \mathrm{~min}$ in $38(66 \%)$ subjects. For EVH and field exercise tests, the interval between tests was $9.2(2-20)$ days, the mean maximal time difference was $149(0-340)$ min and was within $90 \mathrm{~min}$ in $13(39 \%)$ subjects.

\section{AHR to methacholine, AMP and mannitol}

Twenty-five $(43 \%)$ subjects were hyperresponsive to one of these stimuli. Hyperresponsiveness to methacholine was present in 23 subjects (median (interquartile range; IOR) $\mathrm{PD}_{20} \mathrm{FEV}_{1}$ $486 \mu \mathrm{g}(342-929))$ and to AMP in five (8.3\%) subjects (median (IOR) $\left.\mathrm{PD}_{20} \mathrm{FEV}_{1} 35.5 \mathrm{mg}(15.8-37.4)\right)$. Three (5.1\%) subjects were hyperresponsive to mannitol, with individual $\mathrm{PD}_{15} \mathrm{FEV}_{1}$ of 315,560 and $635 \mathrm{mg}$.

The response-dose ratios for AMP and mannitol were not significantly different in skiers with and without AHR to methacholine (figure 1). There was a significant correlation between the decrements in $\mathrm{FEV}_{1}$ during AMP and mannitol provocation $\left(\mathrm{N}=58, \mathrm{r}_{\mathrm{s}}=0.33, \mathrm{p}=0.011\right)$.

Baseline $\mathrm{FEV}_{1}$ (mean (SD) L, \% predicted (SD)) on each study day was within normal limits (AMP 4.04 (0.74), 103.3 (9.6); mannitol $4.02(0.77)^{*}, 102.5$ (9.7); methacholine $4.12(0.79)$, 105.1 (10.3)). $\mathrm{FEV}_{1}$ was significantly lower before challenge with mannitol than with methacholine $\left({ }^{*} \mathrm{p}<0.05\right)$. Forced vital capacity and $\mathrm{FEV}_{1}$ /forced vital capacity ratios were also within normal limits (data not shown).

\section{AHR to EVH and field exercise}

Average minute volume (mean (SD)) during EVH was 108.2 (24.7) L and 77.6 (10.2) \% of maximum minute ventilation.

Of 33 skiers, three (9\%) and six (18\%) skiers were hyperresponsive to EVH and field exercise tests, respectively. In those without previous methacholine hyperresponsiveness, AHR to either stimulus was detected in four subjects. No subject was positive to both tests. Of $14(42 \%)$ skiers with methacholine hyperresponsiveness (median (IOR) $\mathrm{PD}_{20} \mathrm{FEV}_{1}$ methacholine $396.5 \mu \mathrm{g}$ (303.5-904.5)), three were hyperresponsive to either test and one was hyperresponsive to both tests.

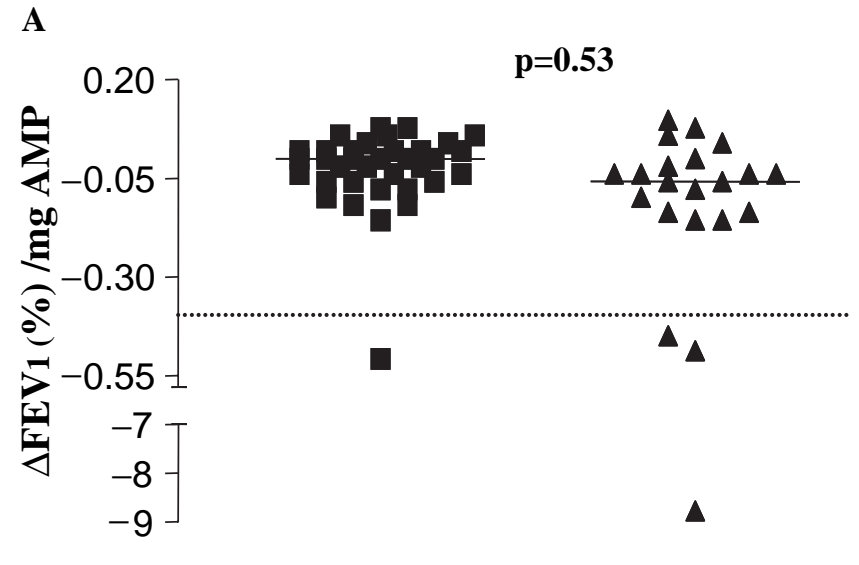

\section{Negative $(\mathrm{N}=35) \quad$ Positive $(\mathrm{N}=23)$ Methacholine challenge}

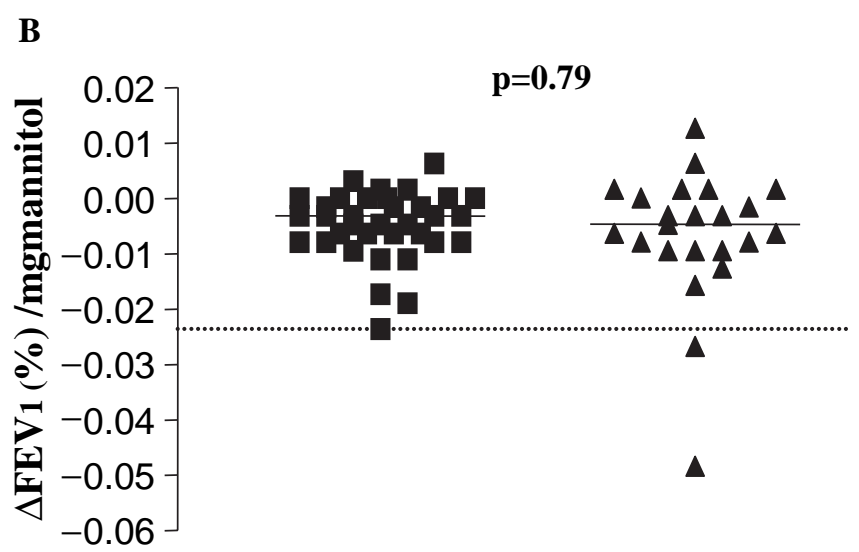

\section{Negative $(\mathbf{N}=35) \quad$ Positive $(\mathbf{N}=23)$ Methacholine challenge}

Figure 1 Response-dose ratios for adenosine 5'-monophosphate (AMP) (A) and mannitol (B) in 58 skiers by hyperresponsiveness to methacholine. Response-dose ratio at or below stippled line indicates hyperresponsiveness to AMP and mannitol. Bars represent median values. FEV ${ }_{1}$, forced expiratory volume in $1 \mathrm{~s}$.

The area under the curve (AUC) (mean (SD) \% fall FEV, min) after EVH was not significantly different in skiers with and without methacholine hyperresponsiveness $\left(\mathrm{AUC}_{0-20}\right.$ -53 (56) vs -6 (59), $\mathrm{p}=0.061$ ) or field exercise test $\left(\mathrm{AUC}_{0-30}\right.$ -110 (152) vs -19 (131), $p=0.14)$. AHR to any of the five stimuli was present in 20 (61\%) skiers (figure 2$)$.

\section{AHR, asthma symptomatology and doctor-diagnosed asthma}

The relationship between asthma symptomatology and AHR to methacholine, AMP and mannitol is summarised in figure 3. Asthma-like symptomatology was not associated with AHR to any stimulus, with AHR to methacholine being present in seven $(27 \%)$ and $16(50 \%)$ skiers with and without symptoms, respectively. The geometric mean $\mathrm{PD}_{20} \mathrm{FEV}_{1}$ for symptomatic and asymptomatic skiers was $360.0 \mu \mathrm{g}$ (CI 167.2 to 775.3) and $606.1 \mu \mathrm{g}$ (CI 448.7 to 818.8), $\mathrm{p}=0.17$, respectively.

In the methacholine-positive skiers, four reported doctor-diagnosed asthma. Of these, two were on inhaled 


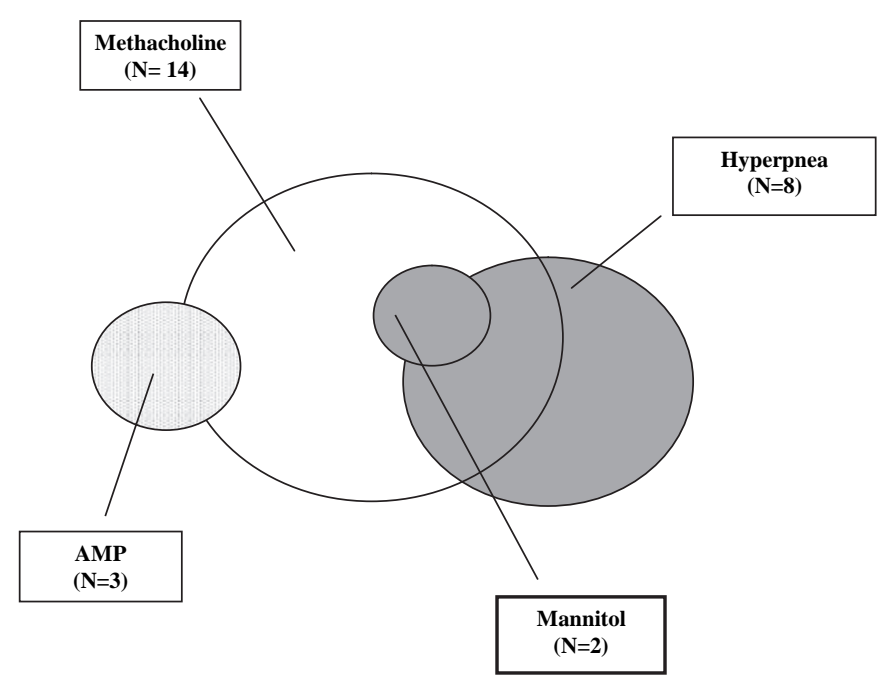

Figure 2 Interrelationship of airway hyperresponsiveness to methacholine, adenosine 5'-monophosphate (AMP), mannitol and hyperpnoea (eucapnic voluntary hyperventilation and field exercise test) in 33 skiers.

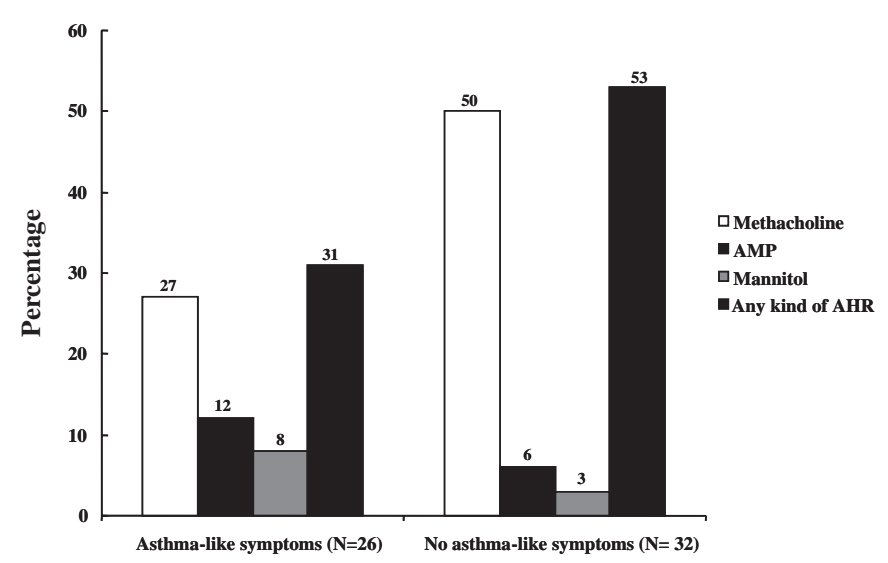

Figure 3 Prevalence of airway hyperresponsiveness to methacholine, adenosine $5^{\prime}$-monophosphate (AMP) and mannitol in 58 skiers related to self-reported asthma symptomatology (wheeze and abnormal breathlessness or chest tightness, either on exertion, at rest or on exposure to irritants within the past year).

corticosteroids and were also hyperresponsive to AMP. One of these skiers was also hyperresponsive to mannitol.

In the methacholine-negative skiers, doctor-diagnosed asthma was reported by six subjects. Of these, three reported the use of inhaled corticosteroids, one was hyperresponsive to mannitol and another was hyperresponsive to AMP.

The distribution of AHR to methacholine, AMP, mannitol, EVH and field exercise by asthma-like symptomatology for 33 skiers is presented in figure 4. One skier with AHR to EVH and five skiers with AHR to exercise did not previously report asthma-like symptoms. One skier with AHR to both tests reported asthma-like symptoms.

\section{Exhaled nitric oxide concentration}

$\mathrm{F}_{\mathrm{E}} \mathrm{NO}$ was measured in 44 subjects before challenge with mannitol, AMP and methacholine. The median (IOR) $\mathrm{F}_{\mathrm{E}} \mathrm{NO}$ on mannitol, methacholine and AMP challenge days was

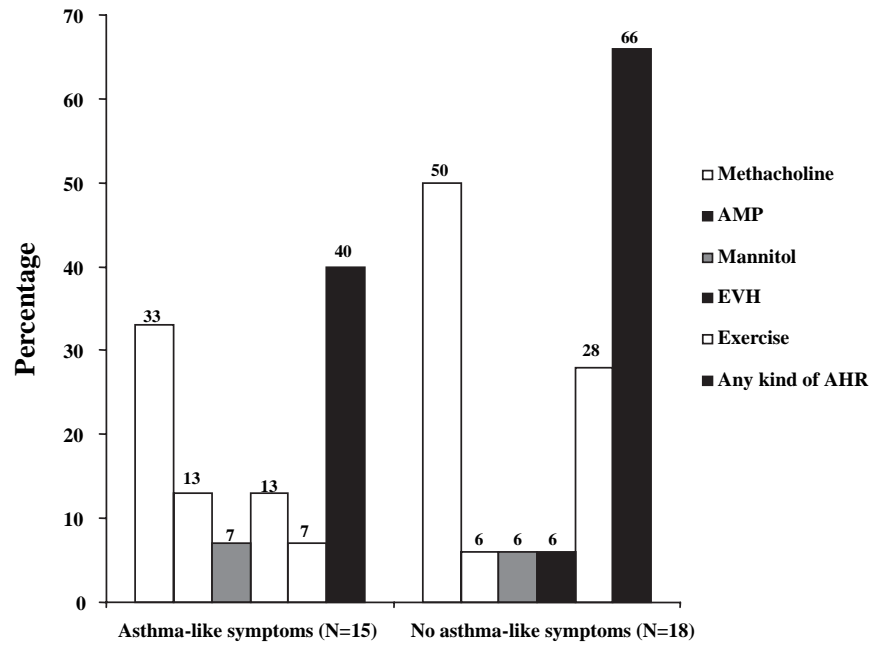

Figure 4 Prevalence of airway hyperresponsiveness (AHR) to methacholine, adenosine $5^{\prime}$-monophosphate (AMP), mannitol eucapnic voluntary hyperventilation (EVH) and field exercise related to asthma symptomatology in 33 skiers.

$4.1 \mathrm{ppb}$ (3.5-5.4), $6.7 \mathrm{ppb}(4.9-8.4)$ and $5.2 \mathrm{ppb}$ (3.9-7.6) $(p<0.001)$, respectively. $\mathrm{F}_{\mathrm{E}} \mathrm{NO}$ was significantly higher on the methacholine $(p<0.001)$ and AMP $(p<0.01)$ challenge days than on the mannitol challenge day.

$\mathrm{F}_{\mathrm{E}} \mathrm{NO}$ before methacholine challenge was not significantly different in skiers with and without hyperresponsiveness to methacholine (median (IOR) 7.3 (4.3-8.6) vs $6.5(5.2-8.2)$ p=0.89). There was no correlation between $\mathrm{F}_{\mathrm{E}} \mathrm{NO}$ and the response-dose ratio for methacholine $\left(\mathrm{N}=58, \mathrm{r}_{\mathrm{s}}=-0.074, \mathrm{p}=0.848\right)$.

\section{Allergic sensitisation}

Allergic sensitisation was present in 12 of 16 subjects with self-reported allergy, five of 33 subjects without self-reported allergy and in three of nine subjects who were uncertain about their allergy status.

\section{DISCUSSION}

The airways of elite skiers clearly react in a heterogeneous manner in the training season in the autumn, being more responsive to methacholine than to AMP and mannitol. Methacholine hyperresponsiveness, defined as a $\mathrm{PD}_{20} \mathrm{FEV}_{1}$ of $1800 \mu \mathrm{g}$ or less, was present in $40 \%$ (23) of skiers. By contrast, provocation with AMP and mannitol identified AHR only in five and three subjects, respectively. Additional provocation with $\mathrm{EVH}$ and field exercise tests at 1 month into the competitive season detected hyperresponsiveness in eight skiers.

A number of studies report a high prevalence of AHR in winter athletes. ${ }^{4} 71819$ This study confirms that high prevalence and extends the finding to report that the AHR to methacholine was more prevalent in those not reporting asthma-like symptoms. Furthermore, asthmatic airway inflammation was not a prerequisite for AHR to methacholine. The values for $\mathrm{F}_{\mathrm{E}} \mathrm{NO}$ were normal and consistent with the mild AHR with a $\mathrm{PD}_{20}$ of $486 \mu \mathrm{g}(342-929)$. In the skiers with methacholine hyperresponsiveness, $10(17 \%)$, eight steroid-naive skiers with a $\mathrm{PD}_{20} \mathrm{FEV}_{1}$ of $400 \mu \mathrm{g}$ or less and two skiers on inhaled corticosteroids would have satisfied the criteria for a therapeutic use exemption for $\beta_{2}$ agonists for the 2008 Olympic Games. ${ }^{20}$ An additional four skiers would have qualified by way of the hyperpnoea stimulus. 
The reason for the high prevalence of AHR to methacholine in winter athletes is unclear. One possibility is that breathing large volumes of unconditioned air over long periods during training may cause injury to the airway epithelium, ${ }^{21} 22$ and simply enhance access of the methacholine to the M3 muscarinic receptor on bronchial smooth muscle. The plasma exudation that follows repeated injury may lead to bronchial smooth muscle itself becoming more responsive through a change in its contractile properties. ${ }^{21}$ Another possibility is that the increased cholinergic tone in elite athletes ${ }^{23}$ may increase the receptor sensitivity. Finally, there may have been underreporting and/or reduced perception of symptoms.

In contrast, in the summer athletes reported by Holzer et al ${ }^{10}$ and Pedersen et $a^{13}$ there was a lower prevalence of methacholine AHR and a higher prevalence of AHR to indirect stimuli such as EVH and mannitol ${ }^{11} 13$ The athletes studied by Holzer and colleagues, ${ }^{10} 11$ however, did have a higher prevalence of asthma diagnosis relative to those in the current study. Furthermore, there is a greater frequency of allergic sensitisation in summer athletes. ${ }^{24} 25$ In addition, there is a reduced likelihood of injury to the airways from the need to condition air when exercise is performed under warmer and more humid conditions of summer or in swimming pools.

The indirect stimuli used here are thought to induce bronchoconstriction by the release of mast cell mediators. ${ }^{26-29}$ Four skiers had classic allergic asthma, with AHR to either AMP or mannitol or both. The low prevalence of hyperresponsiveness to AMP in the present study corroborates our previous findings in another population of cross-country skiers. ${ }^{15}$ The prevalence of mannitol hyperresponsiveness in our study is in accordance with that of $9.2 \%$, recently reported by Lund et a ${ }^{30}$ in Danish elite athletes.

Which stimulus should be employed to assess AHR in skiers with respiratory symptoms? In the present study, methacholine hyperresponsiveness that would satisfy International Olympic Committee criteria was present in only 10 of the skiers. For skiers with a negative methacholine test, mannitol provocation detected hyperresponsiveness in only one other skier, and EVH and field exercise during the competitive season identified hyperresponsiveness in two other skiers. In contrast, EVH was superior to methacholine in both elite Danish swimmers and Australian summer sports athletes for diagnosing and evaluating EIB. ${ }^{10}{ }^{13}$ Stensrud et a ${ }^{18}$ have demonstrated that hyperpnoea during field exercise is less sensitive than methacholine for identifying hyperresponsiveness in elite skiers. Increased airway responsiveness to mannitol has a low prevalence in Scandinavian athletes compared with the Australian athletes studied by Holzer et al. ${ }^{11}$ Paradoxically, methacholine responsiveness is greater in athletes from Scandinavia. The reasons for these differences are unknown, but may relate to differences in allergic sensitisation or between the quantity and condition of air during training between the two regions during several seasons. Although studies do not give any clear indication with regard to the preferred stimulus, it would be intuitive to use hyperpnoea as the stimulus, as symptoms in athletes are exercise related. If this stimulus had only been used then eight of 33 (24\%) would have been identified to satisfy the International Olympic Committee criteria.

Our study was limited by the EVH and field exercise tests being performed several months after the other tests and in only $57 \%$ of the original group. Although baseline $\mathrm{FEV}_{1}$ values were not significantly different on each test day (data not shown), selection bias may have influenced the prevalence of hyperresponsiveness to EVH and field exercise. However, tests were performed in 24 of 26 skiers who reported asthma-like symptomatology at inclusion. In addition, responsiveness to methacholine, AMP or mannitol may have altered in the intervening period. Indeed, an increase in methacholine responsiveness by more than twofold has been reported during the competitive part of the season. ${ }^{31} 32$ However, the training burden is reduced during this period and a decrease in methacholine responsiveness cannot be excluded. Irrespective of the shift in responsiveness, the lower prevalence of AHR to EVH and a field exercise test cannot be attributed to an inadequate stimulus. The EVH test was over 8 min instead of the conventional $6 \mathrm{~min}$, and the $4.7 \mathrm{~km}$ ski run was at competition intensity and without a warm-up. We used two time points with a $10 \%$ or greater fall for a positive test, whereas others may have used only one. ${ }^{12}$ With one, the number would rise to 14.

In conclusion, airway responsiveness to direct and indirect bronchoconstrictive stimuli is heterogeneous in elite crosscountry skiers. Methacholine hyperresponsiveness is more prevalent in skiers without asthma-like symptoms than in skiers with asthma-like symptoms. The extremely low prevalence of hyperresponsiveness to the indirect stimuli of AMP, mannitol, EVH and field exercise suggest a different pathogenesis for methacholine hyperresponsiveness in elite skiers and non-athletes. This may be related to allergic sensitisation or training environment with possible consequences for the diagnosis and management of symptoms and AHR in these athletes.

Funding MS-C was financially supported as a post-doctoral research fellow by the Norwegian Research Council. The study was also supported by a study grant from Glaxo SmithKline, Norway.

Competing interests None for MS-C, NC and LB. SDA is the inventor of the mannitol test. The intellectual property is owned by Sydney South West Area Health Service (SSWAHS) and the commercial rights are licensed to Pharmaxis Ltd (Frenchs Forest, NSW, Australia). SDA and JDB own shares in Pharmaxis Ltd, which they purchased themselves but they have not received options. SDA and JDB each receive a $10 \%$ share of the royalties paid to SSWAHS.

\section{What is already known on this topic}

- AHR to methacholine in winter athletes is commonly used as objective evidence to justify the use of asthma medication.

\section{What this study adds}

- This study demonstrates that AHR to methacholine is more prevalent in asymptomatic than in symptomatic skiers.

- Airway injury during training may be important in the pathogenesis of AHR to methacholine in winter athletes.

Ethics approval This study was conducted with the approval of the Regional Ethics Committee in Trondheim.

Patient consent Obtained.

Provenance and peer review Not commissioned; externally peer reviewed. 


\section{REFERENCES}

1. Rice SG, Bierman CW, Shapiro GG, et al. Identification of exercise-induced asthma among intercollegiate athletes. Ann Allergy 1985;55:790-3.

2. Voy RO. The U.S. Olympic Committee experience with exercise-induced bronchospasm, 1984. Med Sci Sports Exerc 1986;18:328-30.

3. Weiler JM, Metzger WJ, Donnelly AL, et al. Prevalence of bronchial hyperresponsiveness in highly trained athletes. Chest 1986;90:23-8.

4. Larsson K, Ohlsén P, Larsson L, et al. High prevalence of asthma in cross country skiers. BMJ 1993;307:1326-9.

5. Kaelin M, Brändli O. Exertional asthma in Swiss top-ranking athletes. Schweiz Med Wochenschr 1993;123:174-82.

6. Rupp NT, Brudno DS, Guill MF. The value of screening for risk of exercise-induced asthma in high school athletes. Ann Allergy 1993;70:339-42.

7. Sue-Chu M, Larsson L, Bjermer L. Prevalence of asthma in young cross-country skiers in central Scandinavia: differences between Norway and Sweden. Respir Med 1996;90:99-105.

8. International Olympic Medical Commission. Beta2 adrenoceptor agonists and the Olympic Winter Games in Salt Lake City. http://www.olympic.org. (accessed Nov 2001-Feb 2002).

9. Rundell KW, Anderson SD, Spiering BA, et al. Field exercise vs laboratory eucapnic voluntary hyperventilation to identify airway hyperresponsiveness in elite cold weather athletes. Chest 2004;125:909-15.

10. Holzer K, Anderson SD, Douglass J. Exercise in elite summer athletes: challenges for diagnosis. J Allergy Clin Immunol 2002;110:374-80.

11. Holzer K, Anderson SD, Chan HK, et al. Mannitol as a challenge test to identify exercise-induced bronchoconstriction in elite athletes. Am J Respir Crit Care Med 2003;167:534-7.

12. Dickinson JW, Whyte GP, McConnell AK, et al. Screening elite winter athletes for exercise induced asthma: a comparison of three challenge methods. $\mathrm{Br} \mathrm{J}$ Sports Med 2006;40:179-82; discussion 179-82.

13. Pedersen L, Winther S, Backer V, et al. Airway responses to eucapnic hyperpnea, exercise, and methacholine in elite swimmers. Med Sci Sports Exerc 2008; 40:1567-72.

14. Crapo RO, Morris AH, Gardner RM. Reference spirometric values using techniques and equipment that meet ATS recommendations. Am Rev Respir Dis 1981;123:659-64.

15. Sue-Chu M, Henriksen AH, Bjermer L. Non-invasive evaluation of lower airway inflammation in hyper-responsive elite cross-country skiers and asthmatics. Respir Med 1999;93:719-25.

16. Anderson SD, Brannan J, Spring J, et al. A new method for bronchialprovocation testing in asthmatic subjects using a dry powder of mannitol. Am J Respir Crit Care Med 1997;156:758-65.
17. Henriksen AH, Sue-Chu M, Holmen TL, et al. Exhaled and nasal NO levels in allergic rhinitis: relation to sensitization, pollen season and bronchial hyperresponsiveness. Eur Respir J 1999;13:301-6.

18. Stensrud T, Mykland KV, Gabrielsen K, et al. Bronchial hyperresponsiveness in skiers: field test versus methacholine provocation? Med Sci Sports Exerc 2007;39:1681-6.

19. Leuppi JD, Kuhn M, Comminot C, et al. High prevalence of bronchial hyperresponsiveness and asthma in ice hockey players. Eur Respir J 1998;12:13-16.

20. International Olympic Medical Commission. Beta2 adrenoceptor agonists and the Olympic Games in Beijing. http://www.olympic.org. (accessed March 2008)

21. Anderson SD, Kippelen P. Airway injury as a mechanism for exercise-induced bronchoconstriction in elite athletes. J Allergy Clin Immunol 2008;122:225-35; quiz 236-7.

22. Chimenti L, Morici G, Paternò A, et al. Endurance training damages small airway epithelium in mice. Am J Respir Crit Care Med 2007;175:442-9.

23. Langdeau JB, Turcotte $H$, Desagné $P$, et al. Influence of sympatho-vagal balance on airway responsiveness in athletes. Eur J App/ Physiol 2000;83:370-5.

24. Bousquet P-J, Chinn S, Janson C, et al. Geographical variation in the prevalence of positive skin tests to environmental aeroallergens in the European Community Respiratory Health Survey I. Allergy 2007;62:301-9.

25. Katelaris $\mathbf{C H}$, Carrozzi FM, Burke TV, et al. A springtime olympics demands special consideration for allergic athletes. J Allergy Clin Immunol 2000;106:260-6.

26. Brannan JD, Gulliksson M, Anderson SD, et al. Evidence of mast cell activation and leukotriene release after mannitol inhalation. Eur Respir J 2003;22:491-6.

27. Kippelen P, Larsson J, Anderson SD, et al. Acute effects of beclomethasone on hyperpnea-induced bronchoconstriction. Med Sci Sports Exerc 2010;42:273-80.

28. Crummy $\mathbf{F}$, Livingston $\mathbf{M}$, Ennis $\mathbf{M}$, et al. Mast cell mediator release in nonasthmatic subjects after endobronchial adenosine challenge. J Allergy Clin Immunol 2004;114:34-9.

29. O'Sullivan S, Dahlén B, Dahlén SE, et al. Increased urinary excretion of the prostaglandin D2 metabolite 9 alpha, 11 beta-prostaglandin F2 after aspirin challenge supports mast cell activation in aspirin-induced airway obstruction. J Allergy Clin Immunol 1996;98:421-32.

30. Lund TK, Pedersen L, Anderson SD, et al. Are asthma-like symptoms in elite athletes associated with classical features of asthma? Br J Sports Med 2009;43:1131-5.

31. Heir $\mathbf{T}$, Larsen $\mathrm{S}$. The influence of training intensity, airway infections and environmental conditions on seasonal variations in bronchial responsiveness in crosscountry skiers. Scand J Med Sci Sports 1995;5:152-9.

32. Hemingson HB, Davis BE, Cockcroft DW. Seasonal fluctuations in airway responsiveness in elite endurance athletes. Can Respir J 2004;11:399-401. 